\title{
Oslo96-reformen og faglig oppdateringspraksis
}

\begin{abstract}
BAKGRUNN Vi har tidligere vist at leger som hadde fulgt studieordningen 0slo96, 2-3 år etter studieslutt brukte noe mer tid på oppdatering enn andre leger fra Universitetet i Oslo, men mindre tid enn leger fra Universitetet i Bergen. Hensikten med denne undersøkelsen er å se om disse forskjellene er endret 5,5-7 år etter avsluttet studium.
\end{abstract}

MATERIALE OG METODE Vi benyttet spørreskjemadata fra siste studiekull fra gammel studieordning ved Universitetet i Oslo (fullført utdanning 2001) og andre årskull fra Oslo96-ordningen (fullført 2003) samt fra årskullet som ble uteksaminert ved Universitetet i Bergen i 2003. Data ble samlet inn 5,5-7 år etter studieslutt (T2) og sammenholdt med tilsvarende data fra 2-3 år etter avsluttet studium (T1). Kun respondenter som svarte på alle spørsmål ved både T1 og T2 er inkludert.

RESULTATER Svarprosenten varierte mellom 55 og 59 i de tre utvalgene. 5,5-7 år etter avsluttet utdanning var det ingen forskjell i tid brukt på oppdatering mellom Oslo96-leger (median $230 \mathrm{~min} / \mathrm{uke}$ ) og leger utdannet før Oslo96-reformen eller ved Universitetet i Bergen (begge median $240 \mathrm{~min} / \mathrm{uke}$ ). I alle tre gruppene var det en statistisk signifikant økning fra T1 til T2 i rapportert bruk av internett for faglig oppdatering. Kurs og konferanser var de foretrukne oppdateringsformene.

FORTOLKNING Det var ikke mulig å påvise noen sammenheng mellom studieordning og legenes oppdateringsvaner.

I 1996 innførte Det medisinske fakultet ved Universitetet i Oslo en ny studieordning, kalt Oslo96. En tradisjonell studiemodell med preklinisk og klinisk fase ble erstattet av en modell med elementer av både tradisjonell undervisning og problembasert læring (PBL). Den nye studieordningen var altså ingen ren PBL-modell - det var en undervisningsmessig hybrid som også skulle være fagintegrerende. Reformen var hovedsakelig av pedagogisk og organisatorisk karakter, og smågruppeundervisning og tidlig pasientkontakt sto sentralt i den nye modellen. Blant målsettingene var å utdanne kandidater som skulle være forberedt på et yrkesliv med behov for kontinuerlig faglig oppdatering og kompetanseøkning (1).

Det finnes en omfattende forskningslitteratur der man har sett på effekter av problembasert læring på medisinstudenters trivsel, kunnskapstilegnelse og ferdigheter i studiet (2-5), men få der man har vurdert langtidseffektene av reformer innen medisinstudiet. I en studie fra Nederland var det positive langtidseffekter - leger som hadde gjennomgått PBL-baserte studieopplegg skåret høyere på en rekke ferdigheter, inkludert bruk av informasjonsressurser, enn leger som hadde gjennomgått «tradisjonelle» studieopplegg (6).

Universitetet i Oslo har lagt forholdene til rette for langsiktig evaluering av Oslo96 (7), og Oslo96-studenter, studenter fra den gamle studieordningen i Oslo og studenter uteks- aminert ved Universitetet $\mathrm{i}$ Bergen er blitt fulgt opp med spørreskjemaundersøkelser. Vi har tidligere rapportert at Oslo96-studenter ved studieslutt var mer tilfredse med undervisningen og hadde mer aktive læringsstrategier enn de andre to gruppene (8).

I spørreskjemaundersøkelsen foretatt 2-3 år etter avlagt embetseksamen fant vi bare ubetydelige forskjeller i oppdateringsvaner, selvvurderte kliniske ferdigheter og pasientkommunikasjon, og det var ikke mulig å påvise noen egen Oslo96-effekt (9). Oslo96legene anga den gang at de brukte median 3,5 timer i uken på oppdatering, mot 2,5 timer for andre leger fra Universitetet i Oslo og fire timer for gruppen utdannet ved Universitetet i Bergen. I den foreliggende artikkelen følger vi legenes oppdateringsvaner i ytterligere 3-4 år.

Studietiden er viktig for sosialisering til legerollen, men det er også turnustiden og annen arbeidspraksis. Tidligere norske studier tyder på at forskjeller i kliniske ferdigheter mellom leger uteksaminert ved ulike studiesteder viskes ut over tid (10-12). I denne artikkelen spør vi om det er forskjeller i oppdateringspraksis mellom leger som har fulgt ulike studieordninger 5,5-7 år etter endt utdanning.

\section{Materiale og metode}

Data er samlet inn av Senter for profesjonsstudier ved Høgskolen i Oslo og Akershus i forbindelse med prosjektet StudData (13).

\section{Olaf Gjerløw Aasland}

olaf.aasland@legeforeningen.no

LEFO - Legeforskningsinstituttet

og

Avdeling for helseledelse og helseadministrasjon Institutt for helse og samfunn

Universitetet i Oslo

Jannecke Wiers-Jenssen

NIFU - Nordisk institutt for studier av innovasjon, forskning og utdanning

\section{HOVEDBUDSKAP}

5,5-7 år etter endt utdanning finner vi ingen forskjell i tid brukt på oppdatering mellom Oslo96-leger og leger som er utdannet ved Universitetet i Oslo før reformen eller ved Universitetet i Bergen

Det var en signifikant økning i bruk av internett for faglig oppdatering i alle tre gruppene

Kurs og konferanser var de foretrukne oppdateringsformene 
Dette er en spørreskjemaundersøkelse som omfatter mange typer profesjonsutdanninger. Det er spesifikke spørsmål til ulike utdanningsgrupper, inkludert leger.

Fra Universitetet i Oslo er siste studiekull fra gammel studieordning (fullført utdanning 2001, heretter kalt UiO) og andre årskull fra ny studieordning (fullført 2003, heretter kalt Oslo96) inkludert. Fra Universitetet i Bergen er årskullet som ble uteksaminert i 2003 inkludert (heretter kalt UiB). Data er samlet inn tre ganger: omtrent ved studieslutt (T0), 2-3 år etter studieslutt (T1) og 5,5-7 år etter studieslutt (T2) (tab 1).

Bruttoutvalget ble etter hvert noe redusert, ettersom enkelte leger ikke har vært mulige å spore. I denne artikkelen har vi sammenholdt data fra T2 med tidligere publiserte data fra T1 (9). Det var til sammen 314 respondenter ved $\mathrm{T} 1$, men i denne artikkelen bruker vi bare data fra de 280 legene som svarte både ved T1 og T2.

\section{Variabler}

Legene ble bedt om å angi omtrent hvor mye tid (i timer og minutter) de brukte ukentlig på å lese hhv. fagtidsskrifter og -artikler (papir- og nettversjon), faglitteratur (bøker, oppslagsverker o.l.) og faglig informasjon på internett (databaser, nyhetsbrev o.l.). De tre kategoriene omtales i artikkelen som «artikler», «bøker» og «internett». Svarene ble omregnet til minutter per uke.

Videre spurte vi om oppdateringspraksis: «Hvilken betydning vil du si at følgende forhold har for deg når det gjelder faglig oppdatering og vedlikehold?» De følgende 14 alternativer skulle evalueres på en fempunkts Likert-skala fra 5 (svært stor betydning) til 1 (ingen betydning):

- Kurs, seminarer, konferanser

- Formaliserte fagmøter og samlinger på arbeidsplassen (tidsskriftmøter, interne undervisningsmøter etc.)

- Faglig tilbakemelding gjennom epikriser, brev o.l.

- Uformell kontakt med kolleger gjennom telefon eller ved tilfeldige møter

- Medisinske tidsskrifter (papir- og nettversjon)

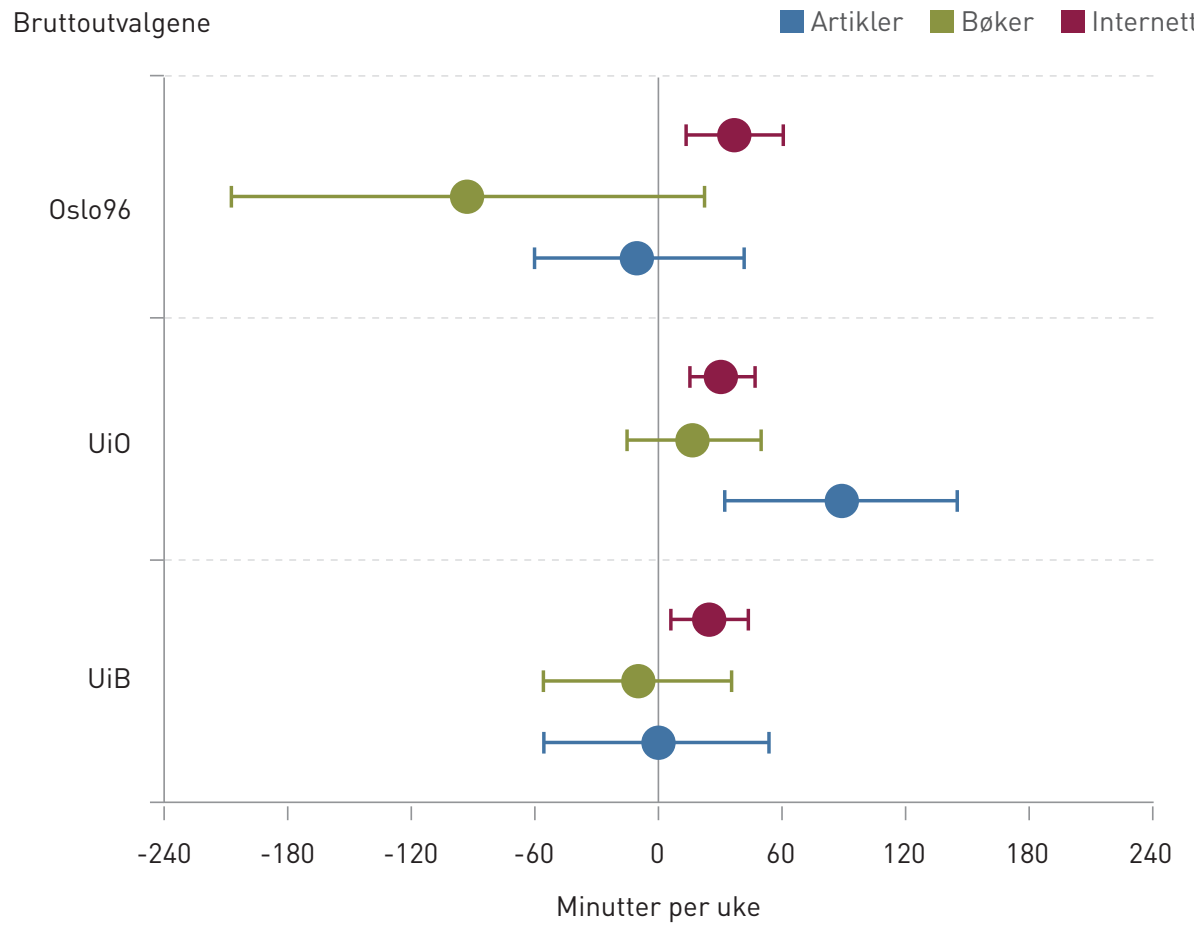

Figur 1 Gjennomsnittlig endring (med $95 \%$ konfidensintervalll fra T1 til T2 i tid brukt på faglig oppdatering, minutter per uke. Positive verdier betyr økning. Hvis konfidensintervallene ikke inkluderer null er endringen statistisk signifikant (paret t-test)

- Medisinsk informasjon på internett (databaser, nyhetsbrev o.1.)

- Lesing av medisinske oppslagsverk, lærebøker o.l.

- Medisinske baser/oppslagsverk på CDrom

- Informasjon, reklamemateriell og besøk fra farmasøytisk industri

- Rundskriv og annet informasjonsmateriell fra offentlige myndigheter (Fylkeslegen, Helsetilsynet, Sosial- og helsedirektoratet, Helse- og omsorgsdepartementet)

- Systematisk evaluering av egen virksomhet (journalgjennomgang etc.)

- Strukturert veiledning (f.eks. i spesialistutdanningen)

- Tilbakemelding fra pasientene

- Informasjon gjennom massemediene (aviser, radio, TV og liknende)

\section{Statistikk}

Signifikanstesting av sammenlikning mellom grupper ble gjort med F-test for normalfordelte og Kruskal-Wallis test for ikke-normalfordelte kontinuerlige variabler. Ved sammenlikning mellom $\mathrm{T} 1$ og $\mathrm{T} 2$ benyttet vi paret $\mathrm{t}$-test, fordi differansene er normalfordelte.

\section{Resultater}

Tabell 1 viser antall leger $\mathrm{i}$ de tre bruttoutvalgene og antall respondenter, kjønnsfordeling og andel over 35 år.

\section{Tid brukt på faglig oppdatering}

Ved T2 varierte den samlede tiden brukt til oppdatering fra ti minutter til 24 timer per uke. Median for alle tre oppdateringsformene samlet var 230 minutter for Oslo96gruppen og 240 minutter for både UiO- og

Tabell 1 Antall leger i de tre bruttoutvalgene og svarprosent samt andel kvinner og andel over 35 år blant respondentene

\begin{tabular}{|c|c|c|c|c|c|c|c|}
\hline & $\begin{array}{l}\text { Uteksamineringsår } \\
\text { og semester }\end{array}$ & $\begin{array}{l}\text { Undersøkelsesår } \\
\text { og semester (T2) }\end{array}$ & $\begin{array}{l}\text { Brutto- } \\
\text { utvalg }\end{array}$ & $\begin{array}{c}\text { Antall } \\
\text { respondenter } \\
\text { (både T1 og T2) }\end{array}$ & $\begin{array}{l}\text { Svarprosent } \\
\text { (både T1 og T2) }\end{array}$ & $\begin{array}{l}\text { Andel } \\
\text { kvinner } \\
(\%)^{1}\end{array}$ & $\begin{array}{c}\text { Andel } \\
\text { over } 35 \text { år } \\
(\%)^{1}\end{array}$ \\
\hline Oslo96 & Vår og høst 2003 & Vår 2009 & 130 & 77 & 59 & 46,8 & 19,5 \\
\hline UiO & Vår og høst 2001 & Vår 2008 & 259 & 147 & 57 & 49,0 & 38,1 \\
\hline $\mathrm{UiB}$ & Vår og høst 2003 & Vår 2009 & 102 & 56 & 55 & 44.6 & 12,5 \\
\hline
\end{tabular}

${ }^{1}$ Gjelder respondentene 
UiB-gruppen. Denne forskjellen er ikke statistisk signifikant ( $p=0,7$, Kruskal-Wallistest).

Figur 1 viser forskjell mellom T1 og T2 i tid brukt på oppdatering fra henholdsvis bøker, artikler og internett. I alle de tre gruppene var det en signifikant økning i tid brukt til oppdatering på internett $(\mathrm{t}=5,6$, $\mathrm{p}<0,001$, paret $\mathrm{t}$-test). Dessuten hadde UiO-legene (de fra gammel ordning) en signifikant økning $\mathrm{i}$ tid brukt på artikler $(\mathrm{t}=3,2$, $\mathrm{p}=0,002)$

\section{Ulike former for faglig oppdatering}

På alle spørsmålene var svarfordelingene tilnærmet normalfordelte. Det var betydelige forskjeller i vektlegging av de forskjellige alternativene. Det mest populære var kurs, seminarer og konferanser (gjennomsnitt 4,3 på en skala fra 1 til 5), fulgt av uformell kontakt med kolleger (gjennomsnitt 3,8), formaliserte fagmøter (gjennomsnitt 3,8), medisinske tidsskrifter (gjennomsnitt 3,7) og medisinske oppslagsverk og fagbøker (gjennomsnitt 3,7).

Alternativer som i gjennomsnitt ble rapportert å ha mindre betydning var medisinsk informasjon på internett (gjennomsnitt 2,1), informasjon fra farmasøytisk industri (gjennomsnitt 2,0) og fra massemediene (gjennomsnitt 1,9). Det var imidlertid nesten ingen forskjell mellom Oslo96-, UiO- og UiB-legene, bortsett fra at Oslo96-gruppen var signifikant lavere enn de to andre på betydningen av formaliserte fagmøter $(3,5$ versus $4,0, p<0,05, F$-test).

\section{Diskusjon}

5-6 år etter endt utdanning bruker legene omtrent fire timer i uken på faglig oppdatering (median 230-240 min), men det er stor individuell variasjon. Dette er samlet sett litt høyere enn det var 2-3 år etter endt utdanning (9). Vi finner imidlertid ingen forskjeller mellom studieordninger eller utdanningssteder i anvendt tid. Heller ikke når det gjelder oppdateringskilder finner vi vesentlige forskjeller mellom UiO-, Oslo96- og UiB-gruppen.

Vi kan altså ikke spore noen «Oslo96effekt» på oppdateringspraksis, slik vi har målt den. Det er ikke dermed sagt at Oslo96studieordningen ikke kan ha langtidseffekter på andre forhold som ikke er målt her. Men vi har tidligere heller ikke funnet vesentlige forskjeller i legenes rapportering av kommunikasjonspraksis og kliniske ferdigheter noen år etter endt utdanning (9).

Det er imidlertid viktig å huske at selve utdanningsløpet bare er én av flere læringsog sosialiseringsarenaer for leger. Erfaringene legene gjør i turnus og senere karriere kan bidra til å viske ut eventuelle forskjeller mellom leger som har gjennomgått forskjellige studieordninger. Vi kan ikke utelukke at Oslo96-legene gjennom utdanningsløpet fikk en faglig ballast som har bidratt til en mindre bratt læringskurve etter endt utdanning, eller at de har oppdateringsstrategier som er mer effektive.

Som nevnt innledningsvis finnes det få studier der man har sett på langtidseffekter av reformer $\mathrm{i}$ medisinerutdanningen. En nederlandsk studie har vist positive effekter av PBL-undervisning (6), men der sammenliknes en tradisjonell modell med ren PBLmodell, med vekt på selvrapporterte ferdigheter, som er noe annet enn atferd i form av tidsbruk og praksis, som er målt i vår undersøkelse.

Det er generelt lite forskning på langtidseffekter av utdanningsreformer, og enda færre studier som kan vise varige endringer. Dette har sammenheng med at det er vanskelig å påvise at eventuelle endringer skyldes reformen i seg selv og ikke andre forhold. Videre viser andre studier av leger utdannet ved ulike norske læresteder, med ulike undervisningsopplegg, at forskjellene utviskes over tid (10-12). I lys av dette er det ikke overraskende at det ikke er målbare spor av Oslo96-reformen på oppdateringsvaner 5,5-7 år etter fullført utdanning.

En styrke ved vår studie er at den er basert på gjentatte data fra de samme utvalgene. Dette skulle gi en god reliabilitet, mens validiteten kan være svak fordi vi utelukkende har selvrapporterte data. Én innvending mot undersøkelsen er en noe lavere svarprosent enn ønskelig, men vi mener likevel at en svarprosent på mellom 55 og 60 er akseptabel. Det kan også innvendes at måletidspunktet T2 varierer fra 5,5 år til sju år etter endt utdanning og at gruppene har ulik aldersfordeling. Vi mener imidlertid at oppdateringstid og oppdateringsmåter, slik vi har fremstilt det i denne artikkelen, er godt sammenliknbare både mellom grupper og over tid.

\section{Olaf Gjerløw Aasland (f. 1944)}

er forskningsleder ved LEFO - Legeforskningsinstituttet og professor ved Institutt for helse og samfunn, Universitetet i Oslo. Forfatter har fylt ut ICMJE-skjemaet og oppgir ingen interessekonflikter.

\section{Jannecke Wiers-Jenssen (f. 1966)}

er ph.d. i sosiologi og forskningsleder. Forfatter har fylt ut ICMJE-skjemaet og oppgir ingen interessekonflikter.

\section{Litteratur}

1. Oslo96. Ny grunnutdanning for leger. Oslo: Universitetet i Oslo, Det medisinske fakultet, 1993.

2. Albanese MA, Mitchell S. Problem-based learning: a review of literature on its outcomes and implementation issues. Acad Med 1993; 68: 52-81.

3. Lycke KH. Problembasert læring - dokumenterte effekter og teoretisk forankring. Tidsskr Nor Lægeforen 1995; 115: 718-20.

4. Thomas RE. Problem-based learning: measurable outcomes. Med Educ 1997: 31: 320-9.

5. Colliver JA. Effectiveness of problem-based learning curricula: research and theory. Acad Med 2000; 75: 259-66

6. Schmidt HG, Vermeulen L, van der Molen HT. Longterm effects of problem-based learning: a comparison of competencies acquired by graduates of a problem-based and a conventional medi cal school. Med Educ 2006; 40: 562-7.

7. Wiers-Jenssen J. Skaper ulike studieordninger ulike leger? Bakgrunn for evaluering av Oslo96 medisinutdanningsreformen ved Universitetet i Oslo. Skriftserie 2/2004. Oslo: Norsk institutt for studier av forskning og utdanning, 2004.

8. Wiers-Jenssen J, Aasland OG. Har Oslo96-reformen ført til endringer i studenttilfredshet og studieatferd? Tidsskr Nor Lægeforen 2004; 124 2100-3.

9. Aasland OG, Wiers-Jenssen J. Har Oslo96-reformen hatt betydning for legers oppdatering og ferdighetsnivå? Tidsskr Nor Lægeforen 2007; 127: 2100-4.

10. Gaarder K, Eide NA, Falck G. Turnuslegers ferdigheter i praktiske prosedyrer. Tidsskr Nor Lægeforen 2000. 120. 1512-7.

11. Falck G, Brattebø G, Brinchmann-Hansen $\AA$ et al. Selvrapportert ferdighetsnivå i praktiske prosedyrer etter turnustjeneste i distrikt. Tidsskr Nor Lægeforen 2003; 123: 2265-7.

12. Falck G. Selvrapportert ferdighetsnivå i praktiske prosedyrer etter ny og etter gammel studieordning i Trondheim. Tidsskr Nor Lægeforen 2003; 123: $2268-70$

13. StudData. Database for studier av rekruttering og kvalifisering til profesjonell yrkesutøving. www.hioa.no/Forskning/FoU-SPS/prosjekter/ StudData (17.7.2012).

Mottatt 20.8. 2012, første revisjon innsendt 29.11. 2012, godkjent 6.10. 2013. Redaktør: Siri Lunde Strømme. 